\title{
Tris DBA palladium is an orally available inhibitor of GNAQ mutant uveal melanoma in vivo
}

\author{
Elgilda Musi ${ }^{1}$, Gary K. Schwartz',2, Jae Hyuk Yoo ${ }^{3}$, Shannon J. Odelberg ${ }^{3,4,6}$, Dean Y. \\ $\mathbf{L i}^{3,5,6,7}$, Michael Y. Bonner ${ }^{8}$, Ponniah Selvakumar ${ }^{9}$, Shikha Rao ${ }^{8}$, Linda C. Gilbert ${ }^{8,10}$, \\ Justin Elsey ${ }^{8}$ and Jack L. Arbiser 8,10 \\ ${ }^{1}$ Department of Medicine, Columbia University Medical Center, New York, New York, USA \\ ${ }^{2}$ Herbert Irving Comprehensive Cancer Center, Columbia University College of Medicine, New York, New York, USA \\ ${ }^{3}$ Department of Medicine, Program in Molecular Medicine, University of Utah, Salt Lake City, Utah, USA \\ ${ }^{4}$ Department of Neurobiology and Anatomy, University of Utah, Salt Lake City, Utah, USA \\ ${ }^{5}$ Department of Human Genetics, University of Utah, Salt Lake City, Utah, USA \\ ${ }^{6}$ Department of Internal Medicine, Division of Cardiovascular Medicine, University of Utah, Salt Lake City, Utah, USA \\ ${ }^{7}$ Department of Oncological Sciences, University of Utah, Salt Lake City, Utah, USA \\ ${ }^{8}$ Department of Dermatology, Emory University School of Medicine, Atlanta, Georgia, USA \\ ${ }^{9}$ Department of Pathology and Laboratory Medicine, College of Medicine, University of Saskatchewan, Saskatoon, \\ Saskatchewan, Canada \\ ${ }^{10}$ Veterans Affairs Medical Center, Decatur, Georgia, USA
}

Correspondence to: Jack L. Arbiser, email: jarbise@emory.edu

Keywords: melanoma; chemotherapy

Received: April 09, $2019 \quad$ Accepted: June 05, $2019 \quad$ Published: July 09, 2019

Copyright: Musi et al. This is an open-access article distributed under the terms of the Creative Commons Attribution License 3.0 (CC BY 3.0), which permits unrestricted use, distribution, and reproduction in any medium, provided the original author and source are credited.

\section{ABSTRACT}

Uveal melanoma is a rare but often lethal malignancy and is the leading cause of death due to an ophthalmic condition. Uveal melanoma is often diagnosed at a late stage and has a strong propensity to hepatic metastasis. Recently, the most common driver mutations in uveal melanoma have been identified, predominantly in the G-proteins GNAQ. This pattern differs from that of cutaneous melanoma in which Braf and Nras predominate. There are no current clinically used agents that target GNAQ mutations, unlike the use of Braf inhibitors in cutaneous melanoma. We tested the novel agent Tris DBA palladium and found that it was markedly more effective against GNAQ mutant melanomas than wild type uveal melanomas. Given that ARF6 has recently been discovered as a node in GNAQ mutations, we evaluated the efficacy of Tris DBA palladium on ARF6 signaling and found that it was effective in inhibiting ARF6 activation. Finally, Tris DBA palladium was orally effective against GNAQ mutant melanoma in vivo. Tris DBA Palladium deserves further evaluation as a systemic agent for uveal melanoma.

\section{INTRODUCTION}

Uveal melanoma is an uncommon malignancy that arises from uveal melanocytes. It differs from cutaneous melanoma in several important ways. First, because of its location, detection is often delayed until the lesion reaches an advanced state, and biopsy is more difficult. Second, it appears to be genetically distinct from cutaneous melanoma, with driver mutations in GNAQ and GNA11 being most common in uveal melanoma, while Braf and Nras are the most common driver mutations in cutaneous melanoma $[1,2]$. Finally, uveal melanoma has a distinct propensity to liver metastases, compared with cutaneous metastases, which more commonly metastasize to lymph nodes, lung, and brain [3]. While targeting MAP kinase signaling in cutaneous melanoma with Braf and MEK 
inhibitors have led to increased survival in cutaneous melanoma $[4,5]$, similar targeting of signaling pathways lags behind in uveal melanoma.

We have previously demonstrated activity of a novel small molecule, Tris DBA palladium, in preclinical models of cutaneous melanoma and pancreatic cancer. In cutaneous melanoma, we found that Tris DBA palladium inhibits N-myristoyltransferase 1 (NMT1) and blocks tumor growth in vivo [6]. In pancreatic carcinoma, we demonstrated that Tris DBA palladium inhibits motility and metastases of orthotopic pancreatic carcinoma to the liver [7]. In this report, we demonstrate that Tris DBA palladium is effective in vitro against a panel of human uveal melanoma cell lines with mutations in GNAQ and GNA11. Uveal melanoma without $G$ protein mutations appears less sensitive than GNAQ and GNA11 mutant cells. Surprisingly, we did not observe inhibition of NMT1 protein or activity in treated uveal melanoma cells. Thus, we examined alternative mechanisms of activity of Tris DBA palladium. Recently, ARF6, a small GTPase, has been found to be a major node in GNAQ mutant uveal melanoma [8]. We found that Tris DBA palladium inhibits ARF6 activation in a dose dependent manner in GNAQ mutant melanoma cells. Finally, we discovered that Tris DBA is orally active against GNAQ mutant melanoma in vivo. Thus, Tris DBA palladium deserves further evaluation as a targeted therapy in uveal melanoma.

\section{RESULTS}

\section{Tris DBA palladium inhibits uveal melanoma cell growth}

A panel of human uveal melanoma cell lines, including mutants in GNAQ, GNA11, and wild type were treated with a dose range of Tris DBA palladium, and cell number was evaluated at 24 hours. All cell lines demonstrated sensitivity to Tris DBA palladium, but the GNAQ and GNA11 cell lines were relatively more sensitive than the wild type melanoma cells (Mel290) to the drug. The GI50 value was $1.1 \mu \mathrm{M}$ for the GNAQ and GNA11 mutant cell lines and $2.7 \mu \mathrm{M}$ for the wild type cell line (Figure 1).

\section{Tris DBA palladium inhibits tumor growth in GNAQ xenograft model}

In view of Tris DBA effects observed in vitro, we elected to determine whether this therapy is effective in a GNAQ mutant xenograft mouse model. As shown in Figure 2A, Tris DBA had significant effect on inhibiting tumor growth with more than $50 \%$ inhibition. The therapy resulted in a significantly enhanced reduction in tumor volume ( $p=0.01$ at day 26) when compared to vehicle control. Toxicity was measured along with tumor volume

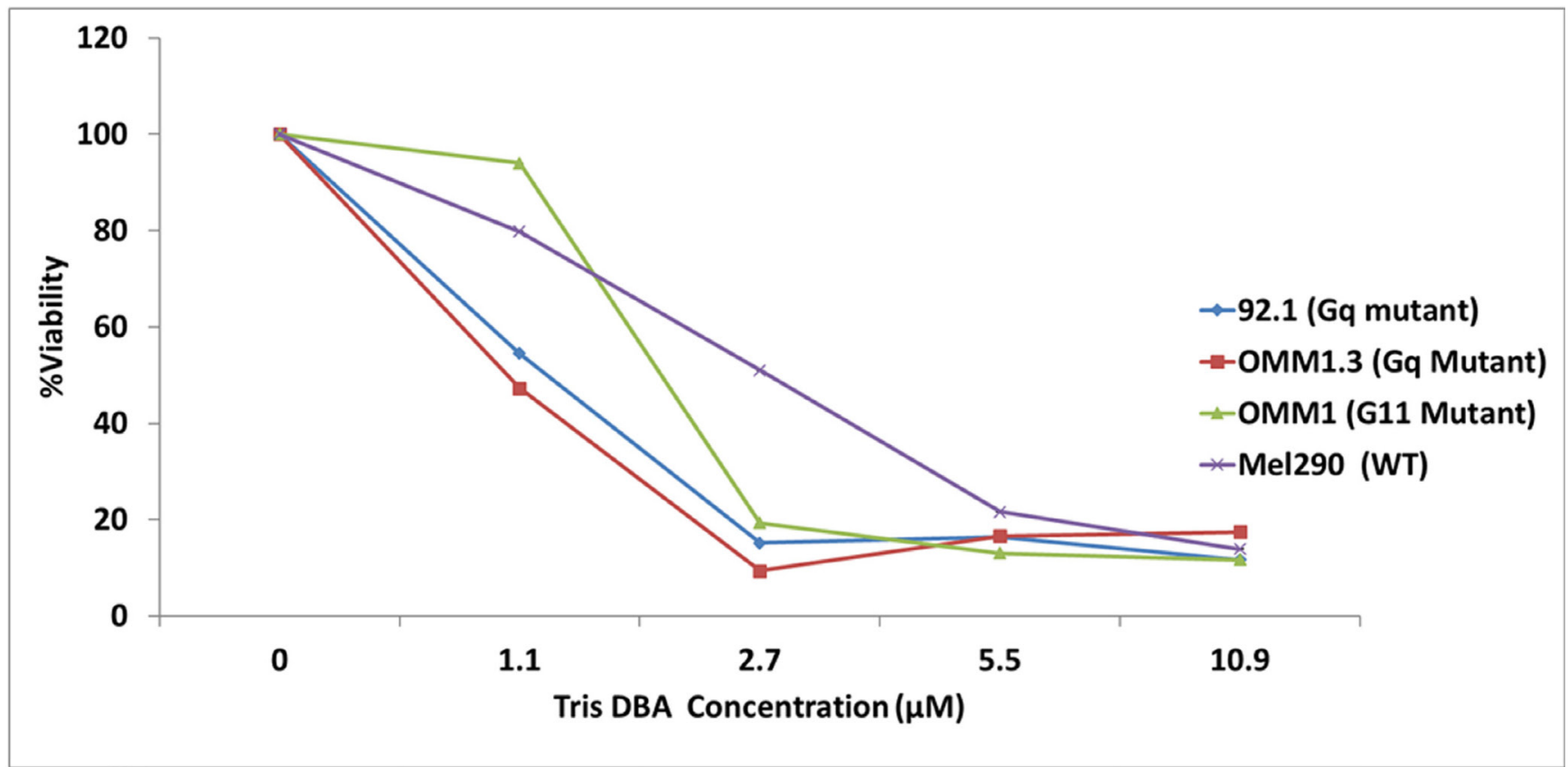

Figure 1: Tris DBA reduces cell viability in GNAQ/GNA11 mutant cell lines. Tris DBA selectively inhibits cell proliferation of GNAQ and GNA11-mutant cells. 92.1(Gq mutant), Omm1.3 (Gq mutant), OMM1 (G11 mutant) and Mel290 (Wild Type) uveal melanoma cell lines were treated with $0,1.1,2.7,5.5$ and $10.9 \mu \mathrm{M}$ of Tris DBA for 24 hours. CCK-8 reagent from Dojindo Molecular Technologies (Rockville, MD, USA), was added after drug treatment to the cells and OD was read at $450 \mathrm{~nm}$. Drug treated samples were presented as percent of control. Results represent the mean of three independent experiments. 
by weight loss, which was less than $10 \%$ for all treatments (Figure 2B).

\section{$\mathrm{N}$-myristoyltransferase activity is not inhibited in uveal melanoma cells}

As previously reported, Tris DBA has been shown to inhibit MAPK, PKC, and AKT pathways in melanoma as a result of NMT-1 blockade [7]. In a uveal melanoma cells lines 92.1 and Mel290, we did not observe suppression of
NMT-1 expression when treated for 24 hours with $2.7 \mu \mathrm{M}$ Tris DBA. This suggests that the inhibitory effect might be independent of NMT-1 (Figure 3A). In fact, p-ERK was activated 24 to 48 hours after drug exposure and p-AKT activation was noted at 2 hours. P-FAK was not affected by the drug. We also examined via immunofluorescence expression of SRC and MARCKS, both involved in the myristoylation pathway, upon treatment with Tris DBA palladium at $5.5 \mu \mathrm{M}$ for 24 hours. We observed no inhibition of either SRC or MARCKS. Remarkably,

A

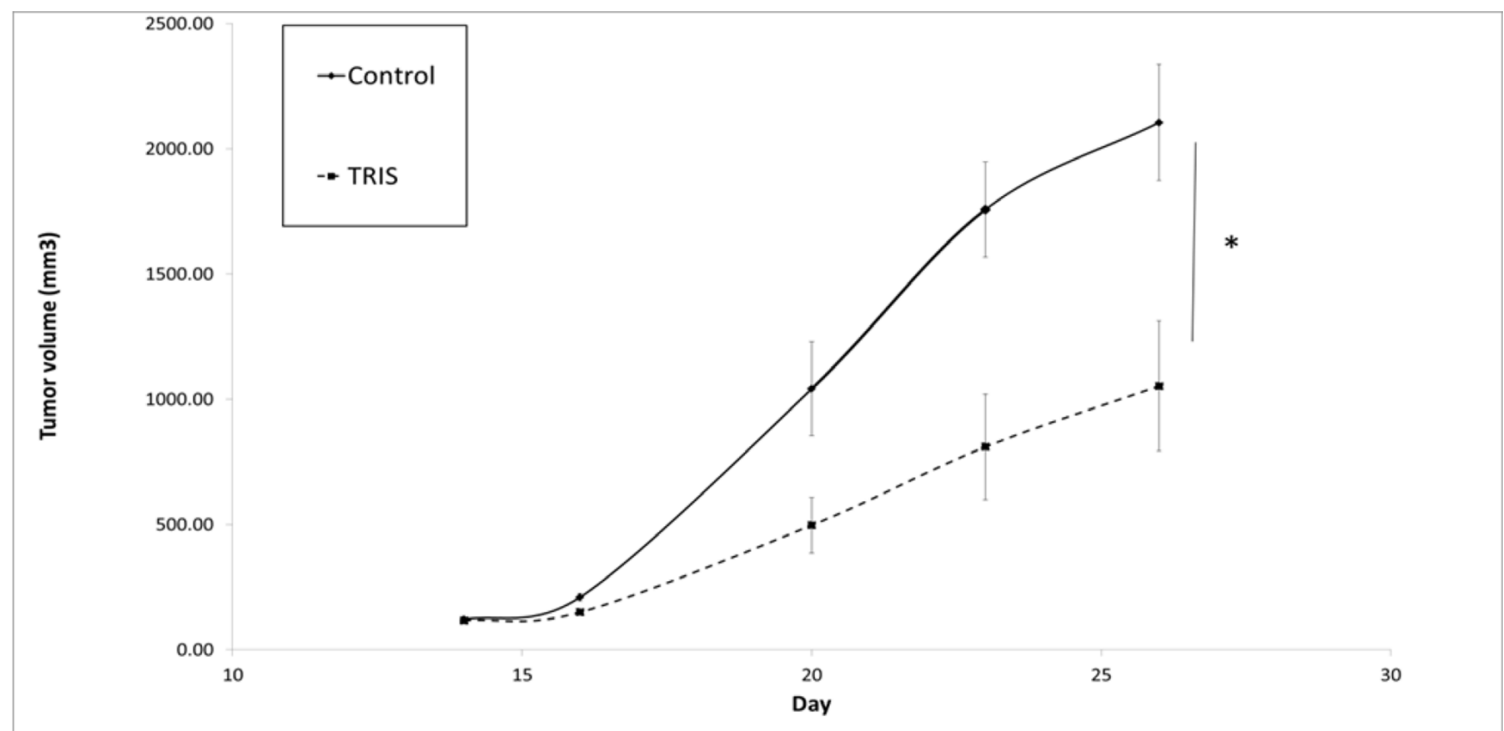

B

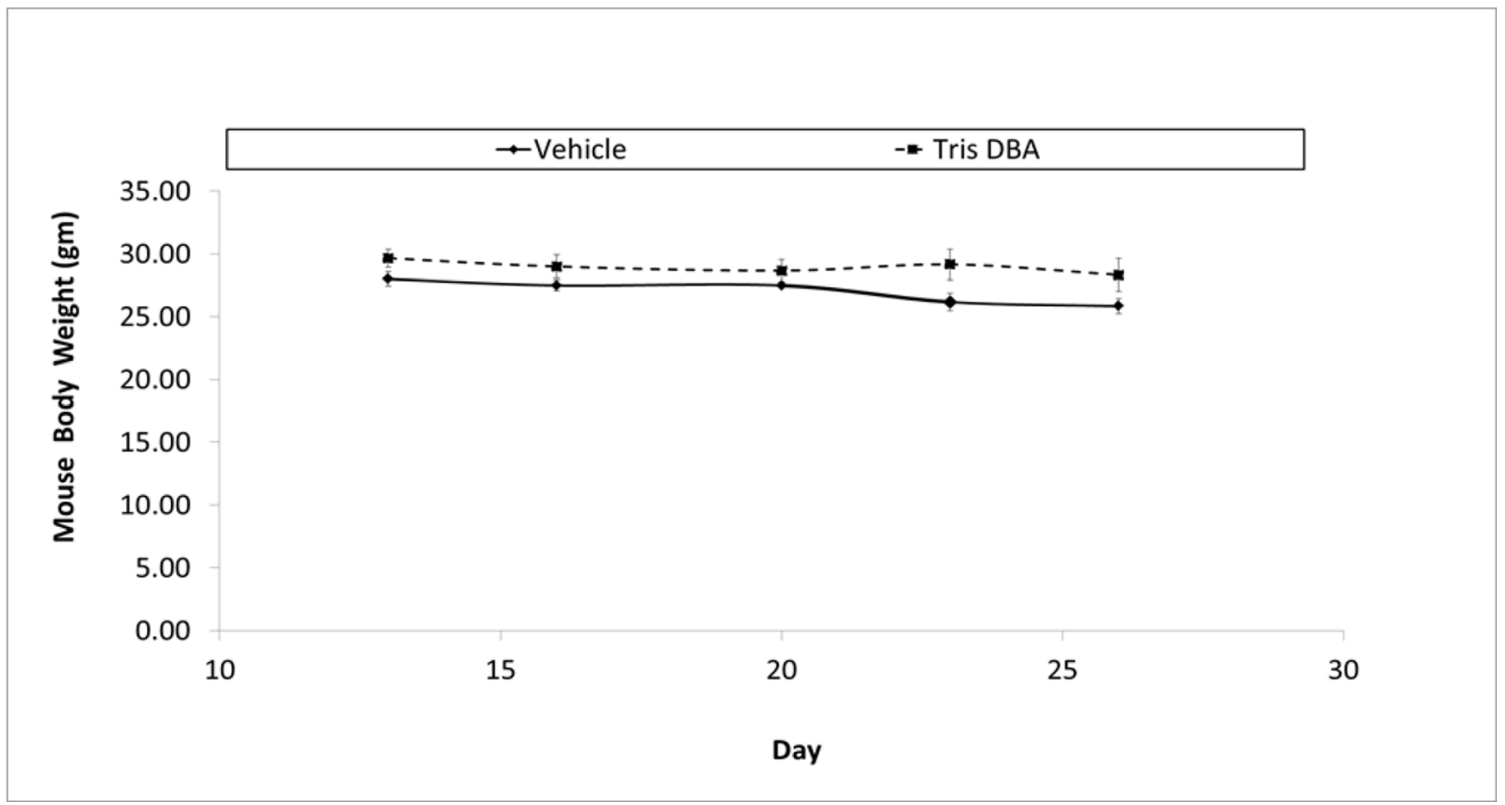

Figure 2: Tris DBA inhibits in vivo tumor growth in a GNAQ mutant xenograft model. (A) Tris DBA inhibited tumor growth in a uveal GNAQ xenograft model. 6-8 week nu/nu SCID female mice were subcutaneously injected with 92.1 uveal melanoma cells. Tris DBA feed began after tumors reached $100 \mathrm{~mm}^{3}$ for a total of two weeks. Tumors were measured with calipers every 2 to 3 days. Tumor volume was compared between groups of mice at various points in time. ${ }^{*} P$-value when compared to Tris DBA was $p=0.01$ at day 26 . (B) Mice body weights were used as measurement of toxicity. 
we saw increased signal of both proteins with treatment localized to the perinuclear area (Figure 3B). To examine whether Tris DBA palladium inhibits previously reported NMT-1 activity, uveal melanoma cell lines were treated with Tris DBA palladium at $5.5 \mu \mathrm{M}$ and $10.9 \mu \mathrm{M}$ for 24 hours and analyzed for NMT-1 activity (Figure 3C and 3D). We observed no significant NMT-1 inhibition in any of the cell lines tested. The xenograft tumors were analyzed for activity and no NMT-1 inhibition was present when mice were given Tris DBA palladium feed for a time period of 14 days.

\section{Tris DBA palladium inhibits ARF6 activity}

To determine the effect of Tris DBA palladium on ARF6 activation, we performed ARF6-GTP pulldown assays on Mel92.1 and Mel202 uveal melanoma cell lines that had been treated with concentrations of Tris DBA palladium ranging from 1 to $5 \mu \mathrm{M}$ (Figure 4). For both cell lines, we observed a concentration-dependent reduction in ARF6 activation (ARG6-GTP) without a change in total ARF6 expression that reached statistical significance at $3 \mu \mathrm{M}$ for Me192.1 and $5 \mu \mathrm{M}$ for Mel202. These results indicate that Tris DBA palladium can inhibit the activation of ARF6 in these uveal melanoma cell lines. It has been reported that GNAQ and ARF6 control the subcellular localization and transactivation of $\beta$-catenin in uveal melanoma cells [8]. Since ARF6 activity was inhibited by Tris DBA, we examined the subcellular localization of $\beta$-catenin expression and found increased $\beta$-catenin levels in the plasma membrane after treatment with $2 \mu \mathrm{M}$ Tris DBA treatment for 24 hours (Figure 4B).

\section{Tris DBA palladium induces apoptosis in GNAQ uveal melanoma}

We next investigated if growth inhibition correlated with apoptosis. We observed caspase 3
A

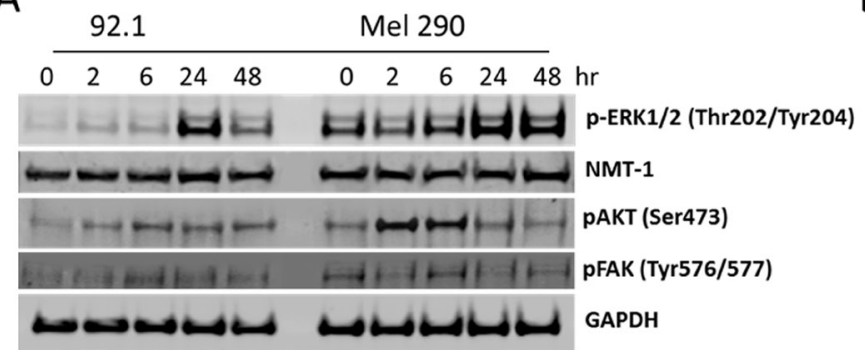

C

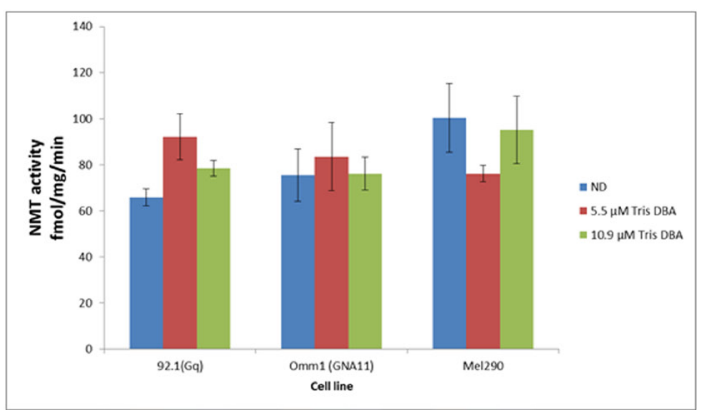

B
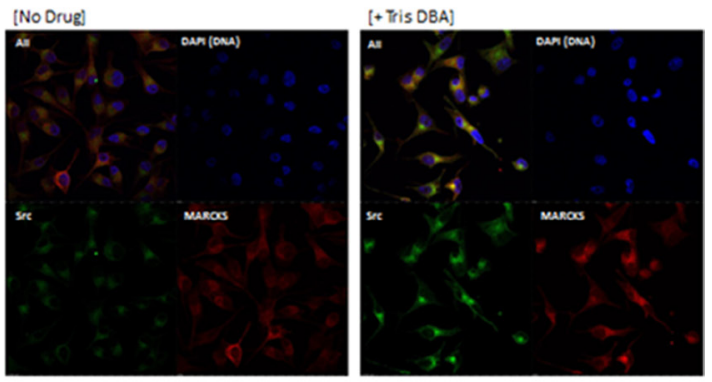

D

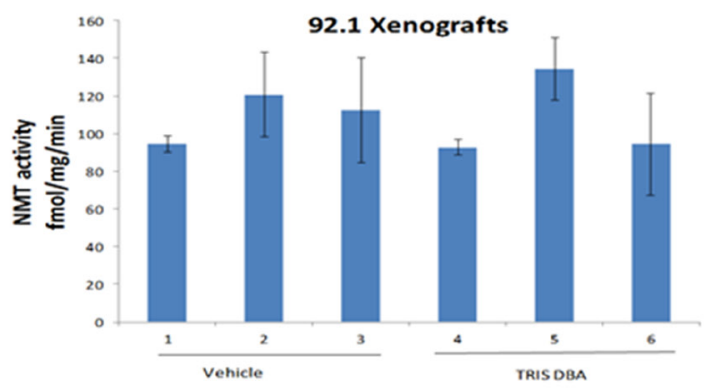

Figure 3: Tris DBA inhibits uveal melanoma tumor growth independent of NMT1. (A) Tris DBA does not inhibit MAPK, AKT or FAK pathways in GNAQ uveal melanoma cells. Western Blot of phospoho-ERK1/2 (Thr202/Tyr204), NMT-1, phosphor-AKT (Ser473) and phospho-FAK (Tyr397) at 0, 2, 6, 24 and 48 hours is shown at $2.7 \mu \mathrm{M}$ Tris DBA. GAPDH was used as a loading control. Briefly, 92.1(Gq mutant) and Mel290 (Wild Type) uveal melanoma cell lines were treated with Tris DBA and lysates were collected in RIPA buffer. Protein concentrations were determined and $30 \mu \mathrm{g}$ of protein was loaded onto a gradient gel. Western Blot was then performed on proteins of interest. (B) Immunofluorescence of 92.1 uveal melanoma cells showing expression of SRC and MARCKS following drug treatment at $2.7 \mu \mathrm{M}$ for 24 hours. Briefly, cells were treated with Tris DBA for 24 hours, after fixation cells were then incubated with primary antibodies overnight at $4^{\circ} \mathrm{C}$. Next day, cells were incubated in fluorescently conjugated secondary antibody and mounted onto slides. (C, D) NMT1 activity was assayed in uveal melanoma cell lines. 92.1(Gq mutant), OMM1 (G11 mutant) and Mel290 (Wild Type) and 92.1 xenografts presenting no inhibition of NMT-1 with drug treatment. Briefly, $20 \mu \mathrm{g}$ of total protein lysate was used and the myristolation reaction was initiated by the addition of freshly generated $[3 \mathrm{H}]$ myristoyl-CoA. The samples were incubated $30^{\circ} \mathrm{C}$ for $30 \mathrm{~min}$. The reaction was terminated and radioactive incorporation was determined by the liquid scintillation counting. 
activation and PARP cleavage after 24 hours of exposure with $5.5 \mu \mathrm{M}$ in all the cell lines tested (Figure $5 \mathrm{~A})$. This effect was concentration dependent with the largest sub-G1 peak noted with $5.5 \mu \mathrm{M}$ of drug (Figure 5C) and also by PARP cleavage induction at similar concentration (Figure 5B). Interestingly, GNAQ WT cell line MEL290 showed less caspase activation and PARP cleavage by western blot. This was confirmed by flow cytometry with $5.5 \mu \mathrm{M}$ of Tris DBA Palladium (Figure 5C).

\section{Gene array of vehicle and treated tumors}

Genes reported upregulated by Tris DBA palladium in vivo include GSTM2, which has been associated with improved prognosis in solid tumors and often demonstrates promoter hypermethylation in advanced cancer $[9,10]$. A second upregulated gene observed here is IFI30/GILT, which has been implicated in regulation of immunity and autoimmunity to melanocyte antigens [11]. One of the most downregulated genes is Cyr61, a pro-inflammatory gene associated with tumorigenesis and IL-8 production [12]. Finally, Cry61 is an established target of ARF6 in uveal melanoma [8]. The transcription factor c-jun is also downregulated, and c-jun is an established target of ARF6 signaling [8] (Table 1).

\section{DISCUSSION}

Uveal melanoma is the leading cause of death due to a condition of the eye [13-15]. Like cutaneous melanoma, uveal melanoma arises from melanocytes, but differs in

A
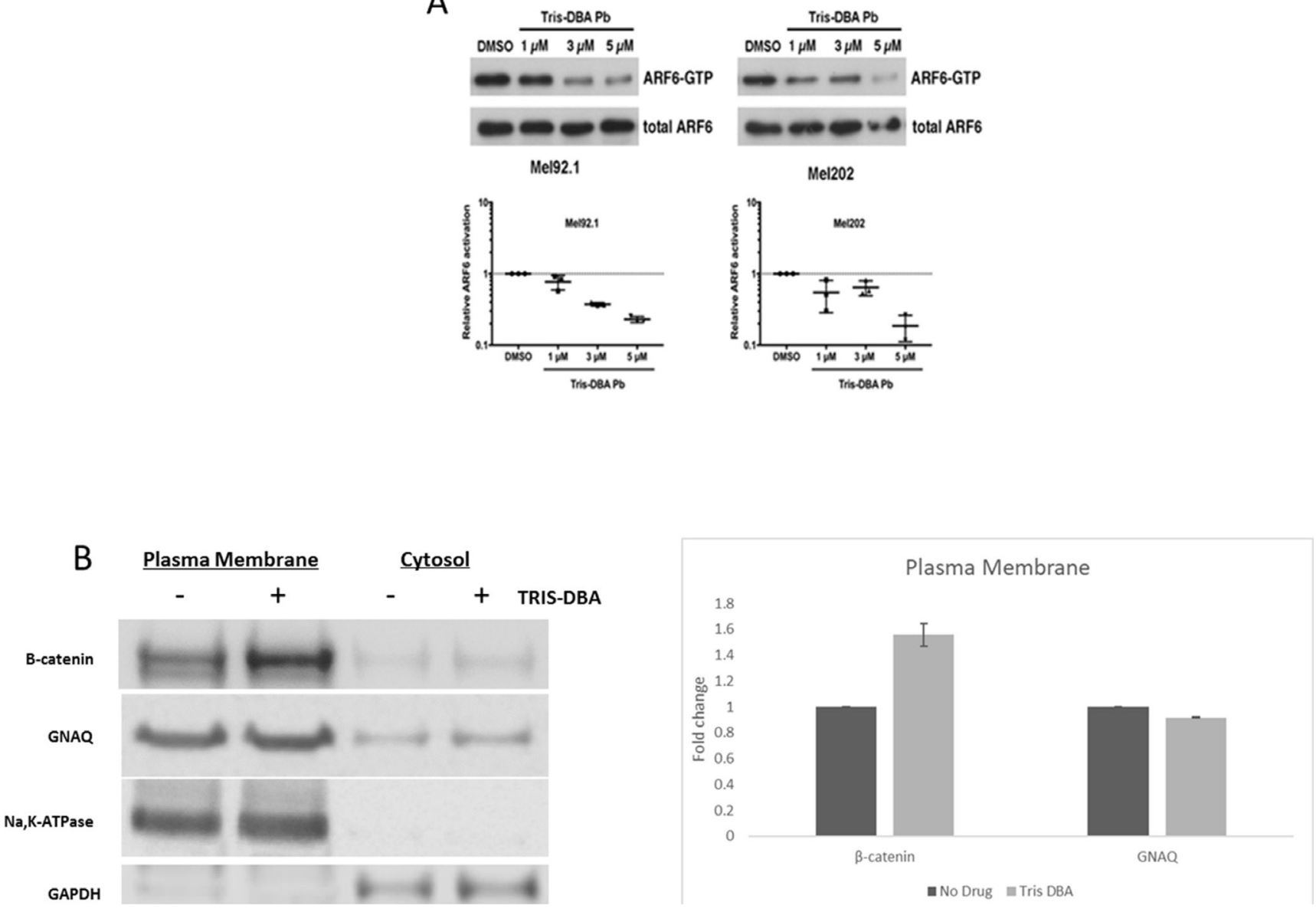

Figure 4: Tris DBA inhibits ARF6 activity and localizes B-catenin to plasma membrane. (A) ARF6-GTP pulldown assay was performed on in vitro Me192.1 and Mel202 cell lines to collect protein indicative of AFR6 activity. Protein collected from pulldown assay was then used to perform Western Blot analysis and compared to DMSO control protein levels which revealed significant inhibition of ARF6 activity at $3 \mathrm{uM}$ in the Mel92.1 cell line and $5 \mathrm{uM}$ in the Mel202 cell line. (B) Plasma membrane and total membrane fractions isolated from 92.1cells treated with no drug or Tris DBA for 24 hours at $2 \mu \mathrm{M}$ concentration. Cells were fractionated to collect plasma membrane. Western Blot of B-catenin and GNAQ is shown. Na,K-ATPase was used as loading control for plasma membrane fractions and GAPDH was used as the loading control for cytosol fractions. Briefly, $100 \times 10^{6}$ cells treated with no drug or Tris DBA were collected and homogenized. Cells were centrifuged and the supernatant (cytosol) was collected. The remaining pellet was purified according to manufacturer instructions (Abcam) for plasma membrane fractions. Quantitation of B-catenin and GNAQ from plasma fractions was performed using Image Studio Lite from LI-COR Biosciences. 
many substantial ways from cutaneous melanoma. First, uveal melanoma is often detected late because of its anatomic location. Second, it has a very strong propensity for liver metastases, as opposed to lymph node, lung, and brain in cutaneous melanoma $[14,15]$. Third, the majority of uveal melanoma is driven by mutations in GNAQ and GNA11, as opposed to Braf and Nras mutations in cutaneous melanoma $[16,17]$. Fourth, uveal melanoma lacks a common UV signature and contains a far smaller mutational burden compared with cutaneous melanoma. These features have made the advances that have benefitted patients with cutaneous melanoma, such as Braf inhibition and immunotherapy less relevant for the patient with uveal melanoma.
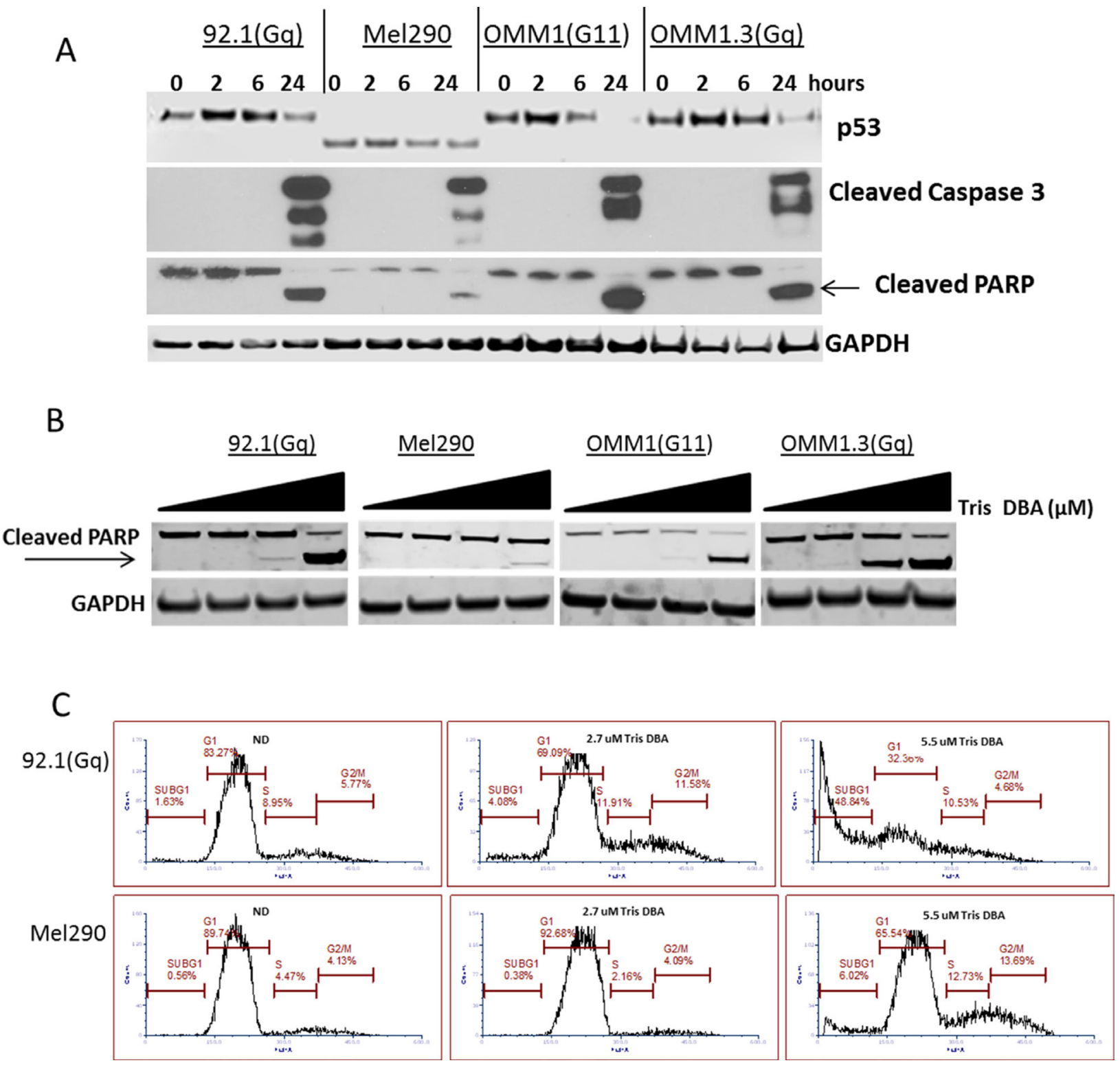

Figure 5: Tris DBA induces apoptosis in GNAQ mutant uveal melanoma. (A) Western Blot of p53, cleaved caspase 3, and cleaved PARP at $0,2,6$, and 24 hours in uveal melanoma cells is shown using $5.5 \mu \mathrm{M}$ Tris DBA concentration. GAPDH was used as a loading control. 92.1(Gq mutant), Mel290 (Wild Type), OMM1 (G11 mutant) and Omm1.3(Gq mutant) uveal melanoma cell lines were treated with Tris DBA and lysates were collected in RIPA buffer. Protein concentrations were determined and $30 \mu \mathrm{g}$ of protein was loaded onto a gradient gel. Western Blot was then performed on proteins of interest. (B) Dose dependent western blot of cleaved PARP using increasing concentrations of 0, 1.1, 2.6 and 5.5 $\mu \mathrm{M}$ of Tris DBA for 24 hours. 92.1(Gq mutant), Mel290 (Wild Type), OMM1 (G11 mutant) and Omm1.3 (Gq mutant) uveal melanoma cell lines were treated with Tris DBA and lysates were collected in RIPA buffer. Protein concentrations were determined and Western Blot was then performed on proteins of interest. (C) Cell cycle analysis with propidium iodide DNA staining using $2.7 \mathrm{uM}$ and $5.5 \mu \mathrm{M}$ Tris DBA treated uveal melanoma cells after 72 hours of treatment. 92.1(Gq mutant) and Mel290 (Wild Type) were treated with Tris DBA. Cells were fixed in $70 \%$ ethanol and kept at $-20^{\circ} \mathrm{C}$. Cells were stained with propidium iodide and analyzed by flow cytometry on a BD Calibur. Analysis was performed using FCS Express 6. 
Table 1: Gene array analysis of in vivo 92.1 xenograft tissues reveals gene profile changes following treatment with Tris DBA enriched food pellets

\begin{tabular}{|c|c|c|c|}
\hline Gene symbol & $p$-value(Tris_DBA vs. control) & $\begin{array}{c}\text { Fold-change(Tris } \\
\text { DBA vs. control) }\end{array}$ & $\begin{array}{c}\text { Fold-change(Tris_DBA vs. control) } \\
\text { (description) }\end{array}$ \\
\hline LINC00342 & 0.0278894 & 1.88409 & Tris_DBA up vs Control \\
\hline MIR4267 & 0.0109544 & 1.67557 & Tris_DBA up vs Control \\
\hline OR1F1 & 0.00796116 & 1.58286 & Tris_DBA up vs Control \\
\hline GSTM2 & 0.0133839 & 1.5688 & Tris_DBA up vs Control \\
\hline PRKXP1 & 0.0283998 & 1.56663 & Tris_DBA up vs Control \\
\hline DDX12P & 0.028791 & 1.56372 & Tris_DBA up vs Control \\
\hline HERC2P4 & 0.0492184 & 1.5589 & Tris_DBA up vs Control \\
\hline SNORD70 & 0.0402876 & 1.53475 & Tris_DBA up vs Control \\
\hline LOC100286922 & 0.00159986 & 1.53324 & Tris_DBA up vs Control \\
\hline ITPKB-IT1 & 0.0239881 & 1.51584 & Tris_DBA up vs Control \\
\hline NPPA-AS1 & 0.00862237 & 1.50476 & Tris_DBA up vs Control \\
\hline IFI30 & 0.0167487 & 1.49128 & Tris_DBA up vs Control \\
\hline LOC729739 & 0.00231828 & 1.48708 & Tris_DBA up vs Control \\
\hline MNS1 & 0.0403036 & 1.47866 & Tris_DBA up vs Control \\
\hline HMGN5 & 0.0252726 & 1.47344 & Tris_DBA up vs Control \\
\hline LOC105369685 & 0.0385378 & 1.47258 & Tris_DBA up vs Control \\
\hline CDK5 & 0.0253059 & 1.46905 & Tris_DBA up vs Control \\
\hline NSA2 & 0.0322093 & 1.46794 & Tris_DBA up vs Control \\
\hline EME1 & 0.00379792 & 1.46696 & Tris_DBA up vs Control \\
\hline IGHV1OR21-1 & 0.00997831 & 1.45999 & Tris_DBA up vs Control \\
\hline MIR4782 & 0.0120561 & 1.44693 & Tris_DBA up vs Control \\
\hline GSTT2 & 0.0414451 & 1.44095 & Tris_DBA up vs Control \\
\hline ADRB2 & 0.0464329 & 1.43553 & Tris_DBA up vs Control \\
\hline TPTE2P1 & 0.0122935 & 1.42744 & Tris_DBA up vs Control \\
\hline ARL17A & 0.01489 & 1.42696 & Tris_DBA up vs Control \\
\hline RXRA & $2.70 \mathrm{E}-05$ & 1.42626 & Tris_DBA up vs Control \\
\hline HAGLR & 0.00426283 & 1.41826 & Tris_DBA up vs Control \\
\hline KLHL38 & 0.00872755 & 1.41106 & Tris_DBA up vs Control \\
\hline ZNF700 & 0.00153304 & 1.40695 & Tris_DBA up vs Control \\
\hline MACROD1 & 0.0361136 & 1.4061 & Tris_DBA up vs Control \\
\hline CHST12 & 0.0421867 & 1.403 & Tris_DBA up vs Control \\
\hline GUSBP1 & 0.0338928 & 1.40203 & Tris_DBA up vs Control \\
\hline ARSA & 0.0241483 & 1.40066 & Tris_DBA up vs Control \\
\hline SNORA11 & 0.0228449 & -3.92074 & Tris_DBA down vs Control \\
\hline JUN & 0.0276787 & -3.03041 & Tris_DBA down vs Control \\
\hline SCARNA4 & 0.0161854 & -2.15055 & Tris_DBA down vs Control \\
\hline CYR61 & 0.0116602 & -1.96086 & Tris_DBA down vs Control \\
\hline SNORD115-22 & 0.0371072 & -1.90193 & Tris_DBA down vs Control \\
\hline RGS2 & 0.0455401 & -1.86268 & Tris_DBA down vs Control \\
\hline SCARNA2 & 0.00236968 & -1.80903 & Tris_DBA down vs Control \\
\hline SNORD115-11 & 0.0465115 & -1.76255 & Tris_DBA down vs Control \\
\hline
\end{tabular}




\begin{tabular}{|c|c|c|c|}
\hline SNORD115-11 & 0.0465115 & -1.76255 & Tris_DBA down vs Control \\
\hline SNORD115-11 & 0.0465115 & -1.76255 & Tris_DBA down vs Control \\
\hline SNORD115-11 & 0.0465115 & -1.76255 & Tris_DBA down vs Control \\
\hline SNORD115-9 & 0.0465115 & -1.76255 & Tris_DBA down vs Control \\
\hline SNORD115-9 & 0.0465115 & -1.76255 & Tris_DBA down vs Control \\
\hline SNORD115-5 & 0.0465115 & -1.76255 & Tris_DBA down vs Control \\
\hline TAS2R46 & 0.0391203 & -1.75125 & Tris_DBA down vs Control \\
\hline MIR1305 & 0.00837122 & -1.66914 & Tris_DBA down vs Control \\
\hline VIM-AS1 & 0.0096019 & -1.64823 & Tris_DBA down vs Control \\
\hline MIR374A & 0.014889 & -1.63399 & Tris_DBA down vs Control \\
\hline SNORD115-39 & 0.0369375 & -1.63077 & Tris_DBA down vs Control \\
\hline HSPA6 & 0.0352236 & -1.62132 & Tris_DBA down vs Control \\
\hline SNORA71D & 0.0413299 & -1.61351 & Tris_DBA down vs Control \\
\hline LINC00312 & 0.0019944 & -1.6131 & Tris_DBA down vs Control \\
\hline EGR1 & 0.0102042 & -1.60692 & Tris_DBA down vs Control \\
\hline MIR3175 & 0.0153444 & -1.54887 & Tris_DBA down vs Control \\
\hline SNORD115-16 & 0.0283855 & -1.47207 & Tris_DBA down vs Control \\
\hline SNORD115-1 & 0.0283855 & -1.47207 & Tris_DBA down vs Control \\
\hline SCARNA18 & 0.0401323 & -1.46856 & Tris_DBA down vs Control \\
\hline HMOX1 & 0.0108223 & -1.45584 & Tris_DBA down vs Control \\
\hline PGK1 & 0.0441437 & -1.45513 & Tris_DBA down vs Control \\
\hline HSF2BP & 0.0213714 & -1.45052 & Tris_DBA down vs Control \\
\hline HIST2H3D & 0.0490749 & -1.43962 & Tris_DBA down vs Control \\
\hline TNFRSF12A & 0.0043647 & -1.43926 & Tris_DBA down vs Control \\
\hline JUNB & 0.00515271 & -1.43517 & Tris_DBA down vs Control \\
\hline SNORD104 & 0.0225254 & -1.43481 & Tris_DBA down vs Control \\
\hline 11-Sep & 0.00318014 & -1.43245 & Tris_DBA down vs Control \\
\hline MAFF & 0.00447969 & -1.42909 & Tris_DBA down vs Control \\
\hline SCARNA8 & 0.0188127 & -1.4263 & Tris_DBA down vs Control \\
\hline HSP90AA6P & 0.0236067 & -1.4202 & Tris_DBA down vs Control \\
\hline PTPRZ1 & 0.0243325 & -1.41038 & Tris_DBA down vs Control \\
\hline LOC100129291 & 0.0364835 & -1.40793 & Tris_DBA down vs Control \\
\hline LINC00910 & 0.000541337 & -1.40159 & Tris_DBA down vs Control \\
\hline
\end{tabular}

Gene array analysis was performed on 92. 1 The triplicate biological samples of tumors from both Tris DBA PD fed mice and Control fed mice were analyzed by NOVA statistical testing for significance $p$ values $<0.05$. Data are normalized to the control treated tumors and presented as fold-change.

Current treatments include surgery, dacarbazine, and ipilimumab, but are not highly efficacious [13]. Experimental approaches such as selumetinib, an orally active MEK1/2 inhibitor, has resulted in increases in progression free survival, but not overall survival [18]. Combination trials of MEK inhibitors with protein kinase C inhibitors are ongoing [19]. Carbozatinib, a small molecule inhibitor of MET and VEGF, has been recently evaluated and is now being tested in combination with temozolomide [20]. Failure of therapies is likely linked to plasticity of signaling, with rapid adaptation of the tumor to alternate signaling pathways upon exposure to signal transduction inhibitors [21].

Advances in the biology of uveal melanoma have been made in recent years. These include discovery of the major driver mutations in uveal melanoma, and prognostic factors for metastatic spread, including monosomy 3 and BAP1 mutation [22-24]. A prognostic panel has subdivided uveal melanoma into class 1 , which has a high level of melanocytic differentiation and better prognosis, 
compared with class 2 , which is more poorly differentiated and prone to metastatic spread.

Recently ARF6 has been found to be a major signaling node in GNAQ mutant melanoma, and blockade of ARF6 has been shown to inhibit multiple pathways activated in uveal melanoma [8]. ARF6 potentiates hepatocyte growth factor/MET signaling, which is a key player in the high rate of hepatic metastasis seen in uveal melanoma $[25,26]$. ARF6 is also associated with potentiation of additional growth factor receptors, including epidermal growth factor receptor (EGFR) signaling, and has been associated with beta 1 integrin signaling and pancreatic cancer metastasis to the liver [27]. Liver metastasis is a common site for solid tumor metastasis, including lung, breast, pancreatic, and uveal melanoma, and ARF6 activation might be a common thread, as ARF6 activation has been shown to be an adverse prognostic factor in these common malignancies $[28,29]$. Of interest, Tris DBA was able to significantly prevent liver metastases of pancreatic cancer [7], and similar signaling processes might underlie hepatic metastases from uveal melanoma.

Tris DBA palladium is a small molecule organometallic compound that has been shown to have activity against multiple preclinical models, including cutaneous melanoma, pancreatic carcinoma, multiple myeloma, and chronic lymphocytic leukemia [6, 7], [30]. Among its previously described modes of action is inhibition of N-myristoyltransferase 1 , an enzyme that catalyzes the addition of myristoyl side chains to substrates such as src family kinases, for which cellular localization is required for optimal activity [31, 32]. Tris DBA palladium also inhibited the orthotopic growth and liver metastatic growth of pancreatic carcinoma. In this study, we demonstrate the efficacy of Tris DBA palladium in vitro and in vivo against uveal melanoma. Most importantly, we demonstrate that Tris DBA palladium inhibits ARF6 activation. Finally, we demonstrate that Tris DBA palladium is orally active against GNAQ mutant uveal melanoma in vivo.

Tris DBA Palladium decreased proliferation in all cell lines, but most drastically in the GNAQ mutant cell lines. However, at an effective dose of $2.7 \mu \mathrm{M}$, we did not see reductions in phosphorylated ERK, Akt, FAK, or total NMT1 levels, implying that Tris DBA was acting independently of these pathways. Tris DBA Palladium caused membrane localization of beta catenin and downregulated Cyr61, both of which are observed upon ARF6 inhibition [8]. However, Tris DBA palladium likely acts through additional ARF6-independent pathways because other factors that have been shown to be downstream of oncogenic GNAQ-ARF6 signaling, such as ERK1/2 [8], are regulated differently in response to Tris DBA palladium. Tris DBA palladium downregulates Cyr61 in vivo, which is associated with inflammatory tumorigenesis, including resistance to chemotherapy and IL-8 production. In addition, a large cohort of small nucleolar RNAs is downregulated. The precise significance of this is not known, but SNORA11 is involved in conversion of pseudouridine to uridine [33]. Several other small nucleolar RNAs are also downregulated, including the SNORD115 family. This suggests that oral Tris DBA palladium appears to have a major impact in tumor RNA splicing. Finally junB was downregulated by Tris DBA palladium, and junB has been shown to mediate protumorigenic effects of TGF beta [34].

Tris DBA is a new and potent anticancer agent. Its intravenous development has been hampered by its poor solubility. In this manuscript, we demonstrate that Tris DBA is orally bioavailable and active against a GNAQ mutant preclinical model of uveal melanoma. While there are multiple targeted therapies for Braf mutant melanoma, development of novel therapies for uveal melanoma lag far behind. In addition to its oral bioavailability, we demonstrate that its mechanism by oral delivery is distinct from its previous mechanism of action against melanoma when given intraperitoneally [35]. This raises the possibility that one could potentially avoid drug resistance to a particular compound by changing its mode of delivery [36]. IND enabling studies and clinical development of Tris DBA are warranted.

\section{MATERIALS AND METHODS}

\section{Cell culture}

All cell lines were maintained in RPMI1640 supplemented with heat inactivated $10 \%$ Fetal Bovine serum, $100 \mathrm{units} / \mathrm{ml}$ penicillin and $100 \mathrm{ug} / \mathrm{ml}$ streptomycin and maintained at $37^{\circ} \mathrm{C}$ and 5\% CO2. 92.1 cells were provided by Dr. William Harbour (Washington University, St. Louis, MO). Omm1.3 was provided by Dr. Bruce Ksander (Harvard Medical School, Boston, MA). Omm1 was kindly provided by Dr. Boris Bastian (University California of San Francisco, San Francisco, CA). Mel290 was from David Folberg (University of Illinois, Chicago, IL).

\section{Cell viability assays}

Cells were plated in a 96-well plate and treated with Tris DBA or DMSO at indicated concentrations for a period of $24 \mathrm{hrs}$. Viability was assessed using Cell Counting Kit from Dojindo Molecular Technologies (Rockville, MD, USA) as per manufacturer's instructions. Briefly, CCK-8 reagent was added after drug treatment to the cells and allowed to incubate at $37^{\circ} \mathrm{C}$ for 1 hour. The OD was read at $450 \mathrm{~nm}$ and drug treated samples were presented as percent of control.

\section{Western blots}

Cells were lysed in radioimmunoprecipitation assay (RIPA) buffer supplemented with protease 
inhibitor cocktail tablet (Roche Diagnostics) and 1 $\mathrm{mmol} / \mathrm{L} \mathrm{Na3VO}$. Equal amounts of protein were loaded and separated on a 4-12\% PAGE gel (Invitrogen). Proteins were transferred to polyvinylidenedifluoride (PVDF) membranes, which were blocked in 5\% nonfat dried milk. Membranes were then incubated with primary and secondary antibody and developed by ECL. Antibodies used to probe were NMT1 and GNAQ (Santa Cruz Biotechnology), phospho-p44/42 MAPK (ERK1/2), Total p44/42 MAPK (ERK1/2), phospho-Akt (Ser473), phospho-FAK (Tyr576/577), Na,K-ATPase, GAPDH, Caspase-3, and Cleaved PARP (Cell Signaling).

\section{Flow cytometry and cell cycle}

Cell cycle analysis was performed after 72 hours of treatment. Cells were fixed in $70 \%$ ethanol and kept at $-20^{\circ} \mathrm{C}$ for overnight or longer. Next day, cells were stained with propidium iodide and MPM-2 antibody for mitotic population distinction and analyzed by flow cytometry on a BD Calibur. Analysis was performed using FCS Express 6.

\section{Immunofluorescence}

Cells were treated with Tris DBA for 24 hours and rinsed three times in PBS, fixed with acetone: methanol $(1: 1)$ at $-20^{\circ} \mathrm{C}$ for 10 minutes and blocked in $3 \%$ BSA for 1 hour at room temperature. Cells were incubated with primary antibodies overnight at $4^{\circ} \mathrm{C}$. Next day, cells were incubated in fluorescently conjugated secondary antibody for 1 hour at room temperature. Cells were mounted in Prolong Gold antifade reagent with DAPI for nuclear staining. Images were captured using a Nikon T1 Eclipse inverted microscope with a CFI Apochromat TIRF 60XC Oil lens. Images were analyzed with Image J.

\section{Plasma membrane protein extraction}

Plasma membrane and total membrane fraction was isolated with Plasma Membrane Protein Extraction Kit (Abcam). Briefly, $100 \times 10^{6}$ cells were treated with no drug or Tris DBA for 24 hours. Cells were scraped in PBS and collected, and homogenization was completed with a Dounce homogenizer. Cells were centrifuged and the supernatant (cytosol) was collected. The remaining pellet was purified according to manufacture instructions and plasma membrane proteins were collected. B-catenin and GNAQ quantitation of plasma fractions was performed using Image Studio Lite from LI-COR Biosciences

\section{$\mathrm{N}$-myristoyltransferase activity assay}

N-myristoyltransferase activity was assayed as described earlier [30, 31]. Briefly, $20 \mu \mathrm{g}$ of total protein lysate was used and the myristolation reaction was initiated by the addition of freshly generated $[3 \mathrm{H}]$
myristoyl-CoA. The samples were incubated $30^{\circ} \mathrm{C}$ for $30 \mathrm{~min}$. The reaction was terminated and radioactive incorporation was determined by the liquid scintillation counting. The background was subtracted from the assays (performed in triplicate) and the NMT activity (mean \pm S.D) was expressed as 1 fmol of myristoyl peptide formed per mg protein per min.

\section{ARF6-GTP pulldown assay}

ARF6-GTP pulldown assays were performed according to manufacturer's instructions using the Arf6 Activation Assay Kit (Cell Biolabs). Briefly, Me192.1 or Mel202 cells were grown in RPMI-1640/10\% FBS to $80 \%$ confluency in $10 \mathrm{~cm}$ tissue culture dishes and then treated with $1 \mu \mathrm{M}$ to $5 \mu \mathrm{M}$ Tris DBA palladium or vehicle ( $0.1 \%$ DMSO in medium) for $3 \mathrm{~h}$ at $37^{\circ} \mathrm{C} / 5 \% \mathrm{CO}_{2}$. Cells were lysed at $4^{\circ} \mathrm{C}$ in $1 \mathrm{X}$ lysis buffer (Cell Biolabs kit) supplemented with protease and phosphatase inhibitor cocktail (ThermoFisher Scientific). Total cell lysate $(0.5 \mathrm{mg})$ was incubated with GGA3-conjugated agarose beads for 1 hour, and then the beads were washed three times with $1 \mathrm{X}$ lysis buffer supplemented with protease and phosphatase inhibitors. Precipitates with beads (ARF6GTP) and total cell lysates (total ARF6) were analyzed by western blot using 5\% nonfat dry milk in PBST as a blocking agent, anti-ARF6 as a primary antibody (diluted 1/1000; Cell Signaling Technology), and a secondary antibody conjugated to horseradish peroxidase (diluted 1/5000; Jackson ImmunoResearch). Signals were detected using Immobilon Western Chemiluminescent HRP Substrate (Millipore). Quantification was performed using scanning densitometry and ImageJ (NIH), and ARF6-GTP levels were normalized to total ARF6 levels.

\section{Xenograft studies}

6-8 week nu/nu SCID female mice bearing subcutaneously injected 92.1 tumors ( 7 mice/group) of $100 \mathrm{~mm} 3$ diameter were treated with vehicle Tris DBA feed (660 ppm (https://www.testdiet.com/). After 2 weeks, two animals from each group were sacrificed and tumors were collected for analysis. Tumors were measured every 2 to 3 days with calipers, and tumor volumes were calculated by the formula $4 / 3 \times r 3[r=$ (larger diameter + smaller diameter)/4. Toxicity was monitored by weight loss. Experiments were carried out under institutional guidelines addressing the proper and humane use of animals. The Memorial Sloan- Kettering Cancer Center Animal Care and Use Committee and Research Animal Resource center approved this study. The study is also in accordance of the Principles of Laboratory Animal Care (NIH Publication No. 85-23, released 1985). 


\section{Gene array and whole-transcriptome expression analysis}

Gene Array of vehicle and drug treated tumors was performed as previously described [36]. Briefly, RNA was extracted using the Qiagen miRNEasy kit $\mathrm{w} /$ on column DNAse treatment as described by the manufacturer. Tissue was lysed and homogenized in Qiazol buffer homogenizer for 40 seconds or until fully disrupted (1 ml Qiazol per $100 \mathrm{mg}$ of tissue). RNA was eluted in $50 \mathrm{ul}$ nuclease free water. $1 \mathrm{ul}$ was used to determine OD (optical density) values on a Nanodrop 1000. 1ul was used to assess sample profiles on the Agilent 2100 using the RNA 6000 Nano assay. $250 \mathrm{ng}$ of total RNA was amplified and labeled using the ThermoFisher Scientific Illuina ${ }^{\mathrm{TM}}$ TotalPrep $^{\mathrm{TM}}$ RNA Amplification kit according to the manufacturer's protocol. Labeled cRNA was hybridized to Illumina HT12 bead array according to the protocol described in the WGGEX Direct Hybridization Assay user guide. Image acquisition and data extraction were performed with an Illumina HiScan laser scanner and GenomeStudio software as previously described [36].

\section{Statistics}

Comparisons were performed using an unpaired, two-tailed, unequal variance Student's $t$-test. Probability values less than 0.05 were considered significant. Data are presented as mean \pm SEM. For ARF6 pulldown assays, a one-way randomized block ANOVA with Dunnett's multiple comparison test was performed following log transformation of the data. Illumina HiScan laser scanner and GenomeStudio software.

\section{Author contributions}

Elgilda Musi: Experimental work; Gary K. Schwartz: Concept development, manuscript writing/ editing; Jae Hyuk Yoo: Experimental work; Shannon J. Odelberg: Experimental work; Dean Y. Li: Concept development, manuscript writing/editing; Michael Y. Bonner: Experimental work; Ponniah Selvakumar: Experimental work; Shikha Rao: Experimental work; Linda C. Gilbert: Experimental work; Justin Elsey: Manuscript editing; Jack L. Arbiser: Concept development, manuscript writing/editing.

\section{ACKNOWLEDGMENTS}

We thank Natalie Giovino at Columbia University Medical Center for her technical assistance in the lab.

\section{CONFLICTS OF INTEREST}

DYL is Senior Vice President of Discovery Sciences and Translational Medicine at Merck \& Co., Inc. and is a cofounder of and scientific advisor to Navigen/A6, Inc. and a co-founder and board member of Recursion Pharmaceuticals. JLA is the inventor of US Patent 8030299

\section{FUNDING}

Dr. Arbiser is supported by NIH RO1 AR47901 and the Rabinowitch-Davis Foundation, Work supported by NHLBI, NIAMS, NCI, and Navigen Pharmaceuticals.

The content is solely the responsibility of the authors and does not necessarily represent the official views of the National Institutes of Health.

\section{REFERENCES}

1. Van Raamsdonk CD, Bezrookove V, Green G, Bauer J, Gaugler L, O’Brien JM, Simpson EM, Barsh GS, Bastian BC. Frequent somatic mutations of GNAQ in uveal melanoma and blue naevi. Nature. 2009; 457:599-602. https://doi.org/10.1038/nature07586. [PubMed]

2. Mori T, Sukeda A, Sekine S, Shibata S, Ryo E, Okano H, Suzuki S, Hiraoka N. SOX10 Expression as Well as BRAF and GNAQ/11 Mutations Distinguish Pigmented Ciliary Epithelium Neoplasms From Uveal Melanomas. Invest Ophthalmol Vis Sci. 2017; 58:5445-51. https://doi. org/10.1167/iovs.17-22362. [PubMed]

3. Rajpal S, Moore R, Karakousis CP. Survival in metastatic ocular melanoma. Cancer. 1983; 52:334-36. https:// doi.org/10.1002/1097-0142(19830715)52:2<334::AIDCNCR2820520225>3.0.CO;2-E. [PubMed]

4. Flaherty KT, Puzanov I, Kim KB, Ribas A, McArthur GA, Sosman JA, O’Dwyer PJ, Lee RJ, Grippo JF, Nolop K, Chapman PB. Inhibition of mutated, activated BRAF in metastatic melanoma. N Engl J Med. 2010; 363:809-19. https://doi.org/10.1056/NEJMoa1002011. [PubMed]

5. Dummer R, Ascierto PA, Gogas HJ, Arance A, Mandala M, Liszkay G, Garbe C, Schadendorf D, Krajsova I, Gutzmer R, Chiarion-Sileni V, Dutriaux C, de Groot JW, et al. Encorafenib plus binimetinib versus vemurafenib or encorafenib in patients with BRAF-mutant melanoma (COLUMBUS): a multicentre, open-label, randomised phase 3 trial. Lancet Oncol. 2018; 19:603-15. https://doi. org/10.1016/S1470-2045(18)30142-6. [PubMed]

6. Kay NE, Sassoon T, Secreto C, Sinha S, Shanafelt TD, Ghosh AK, Arbiser JL. Tris (dibenzylideneacetone) dipalladium: a small-molecule palladium complex is effective in inducing apoptosis in chronic lymphocytic leukemia B-cells. Leuk Lymphoma. 2016; 57:2409-16. https://doi.org/10.3109/10428194.2016.1161186. [PubMed] 
7. Díaz B, Ostapoff KT, Toombs JE, Lo J, Bonner MY, Curatolo A, Adsay V, Brekken RA, Arbiser JL. Tris DBA palladium is highly effective against growth and metastasis of pancreatic cancer in an orthotopic model. Oncotarget. 2016; 7:51569-80. https://doi.org/10.18632/ oncotarget.10514. [PubMed]

8. Yoo JH, Shi DS, Grossmann AH, Sorensen LK, Tong Z, Mleynek TM, Rogers A, Zhu W, Richards JR, Winter JM, Zhu J, Dunn C, Bajji A, et al. ARF6 Is an Actionable Node that Orchestrates Oncogenic GNAQ Signaling in Uveal Melanoma. Cancer Cell. 2016; 29:889-904. https://doi. org/10.1016/j.ccell.2016.04.015. [PubMed]

9. Kresovich JK, Gann PH, Erdal S, Chen HY, Argos M, Rauscher GH. Candidate gene DNA methylation associations with breast cancer characteristics and tumor progression. Epigenomics. 2018; 10:367-78. https://doi. org/10.2217/epi-2017-0119. [PubMed]

10. Wei J, Li G, Zhang J, Zhou Y, Dang S, Chen H, Wu Q, Liu M. Integrated analysis of genome-wide DNA methylation and gene expression profiles identifies potential novel biomarkers of rectal cancer. Oncotarget. 2016; 7:62547-58. https://doi.org/10.18632/oncotarget.11534. [PubMed]

11. Rausch MP, Irvine KR, Antony PA, Restifo NP, Cresswell P, Hastings KT. GILT accelerates autoimmunity to the melanoma antigen tyrosinase-related protein 1 . J Immunol. 2010; 185:2828-35. https://doi.org/10.4049/ jimmunol.1000945. [PubMed]

12. Reid SE, Kay EJ, Neilson LJ, Henze AT, Serneels J, McGhee EJ, Dhayade S, Nixon C, Mackey JB, Santi A, Swaminathan K, Athineos D, Papalazarou V, et al. Tumor matrix stiffness promotes metastatic cancer cell interaction with the endothelium. EMBO J. 2017; 36:2373-89. https:// doi.org/10.15252/embj.201694912. [PubMed]

13. Carvajal RD, Schwartz GK, Tezel T, Marr B, Francis JH, Nathan PD. Metastatic disease from uveal melanoma: treatment options and future prospects. Br J Ophthalmol. 2017; 101:38-44. https://doi.org/10.1136/ bjophthalmol-2016-309034. [PubMed]

14. Grossniklaus HE. Progression of ocular melanoma metastasis to the liver: the 2012 Zimmerman lecture. JAMA Ophthalmol. 2013; 131:462-69. https://doi.org/10.1001/ jamaophthalmol.2013.2547. [PubMed]

15. Donoso LA, Folberg R, Naids R, Augsburger JJ, Shields JA, Atkinson B. Metastatic uveal melanoma. Hepatic metastasis identified by hybridoma-secreted monoclonal antibody MAb8-1H. Arch Ophthalmol. 1985; 103:799-801. https://doi.org/10.1001/archopht.1985.01050060059025. [PubMed]

16. Szalai E, Jiang Y, van Poppelen NM, Jager MJ, de Klein A, Kilic E, Grossniklaus HE. Association of Uveal Melanoma Metastatic Rate With Stochastic Mutation Rate and Type of Mutation. JAMA Ophthalmol. 2018; 136:1115-20. https:// doi.org/10.1001/jamaophthalmol.2018.2986. [PubMed]

17. Merlino G, Herlyn M, Fisher DE, Bastian BC, Flaherty KT, Davies MA, Wargo JA, Curiel-Lewandrowski C, Weber MJ,
Leachman SA, Soengas MS, McMahon M, Harbour JW, et al. The state of melanoma: challenges and opportunities. Pigment Cell Melanoma Res. 2016; 29:404-16. https://doi. org $/ 10.1111 / \mathrm{pcmr} .12475$. [PubMed]

18. Steeb T, Wessely A, Ruzicka T, Heppt MV, Berking C. How to MEK the best of uveal melanoma: A systematic review on the efficacy and safety of MEK inhibitors in metastatic or unresectable uveal melanoma. Eur J Cancer. 2018; 103:41-51. https://doi.org/10.1016/j.ejca.2018.08.005. [PubMed]

19. Sagoo MS, Harbour JW, Stebbing J, Bowcock AM. Combined PKC and MEK inhibition for treating metastatic uveal melanoma. Oncogene. 2014; 33:4722-23. https://doi. org/10.1038/onc.2013.555. [PubMed]

20. Daud A, Kluger HM, Kurzrock R, Schimmoller F, Weitzman AL, Samuel TA, Moussa AH, Gordon MS, Shapiro GI. Phase II randomised discontinuation trial of the MET/VEGF receptor inhibitor cabozantinib in metastatic melanoma. Br J Cancer. 2017; 116:432-40. https://doi. org/10.1038/bjc.2016.419. [PubMed]

21. Arbiser JL, Bonner MY, Gilbert LC. Targeting the duality of cancer. NPJ Precision Oncology. 2017; 1. https://doi. org/10.1038/s41698-017-0026-x. [PubMed]

22. Yavuzyigitoglu S, Mensink HW, Smit KN, Vaarwater J, Verdijk RM, Beverloo B, Brüggenwirth HT, van Marion R, Dubbink HJ, Paridaens D, Naus NC, de Klein A, Kiliç E, and Rotterdam Ocular Melanoma Study Group (ROMS). Metastatic Disease in Polyploid Uveal Melanoma Patients Is Associated With BAP1 Mutations. Invest Ophthalmol Vis Sci. 2016; 57:2232-39. https://doi.org/10.1167/iovs.1518608. [PubMed]

23. Ewens KG, Kanetsky PA, Richards-Yutz J, Purrazzella J, Shields CL, Ganguly T, Ganguly A. Chromosome 3 status combined with BAP1 and EIF1AX mutation profiles are associated with metastasis in uveal melanoma. Invest Ophthalmol Vis Sci. 2014; 55:5160-67. https://doi. org/10.1167/iovs.14-14550. [PubMed]

24. Njauw CN, Kim I, Piris A, Gabree M, Taylor M, Lane AM, DeAngelis MM, Gragoudas E, Duncan LM, Tsao H. Germline BAP1 inactivation is preferentially associated with metastatic ocular melanoma and cutaneous-ocular melanoma families. PLoS One. 2012; 7:e35295. https://doi. org/10.1371/journal.pone.0035295. [PubMed]

25. Surriga O, Rajasekhar VK, Ambrosini G, Dogan Y, Huang R, Schwartz GK. Crizotinib, a c-Met inhibitor, prevents metastasis in a metastatic uveal melanoma model. Mol Cancer Ther. 2013; 12:2817-26. https://doi. org/10.1158/1535-7163.MCT-13-0499. [PubMed]

26. Tushir JS, D'Souza-Schorey C. ARF6-dependent activation of ERK and Rac1 modulates epithelial tubule development. EMBO J. 2007; 26:1806-19. https://doi.org/10.1038/ sj.emboj.7601644. [PubMed]

27. Grossmann AH, Yoo JH, Clancy J, Sorensen LK, Sedgwick A, Tong Z, Ostanin K, Rogers A, Grossmann KF, Tripp SR, Thomas KR, D'Souza-Schorey C, Odelberg SJ, Li DY. The 
small GTPase ARF6 stimulates $\beta$-catenin transcriptional activity during WNT5A-mediated melanoma invasion and metastasis. Sci Signal. 2013; 6:ra14. https://doi.org/10.1126/ scisignal.2003398. [PubMed]

28. Li R, Peng C, Zhang X, Wu Y, Pan S, Xiao Y. Roles of Arf6 in cancer cell invasion, metastasis and proliferation. Life Sci. 2017; 182:80-84. https://doi.org/10.1016/j. 1fs.2017.06.008. [PubMed]

29. Tsai MT, Katagiri N, Ohbayashi N, Iwasaki K, Ohkohchi N, Ding ST, Kanaho Y, Funakoshi Y. Regulation of HGFinduced hepatocyte proliferation by the small GTPase Arf6 through the PIP2-producing enzyme PIP5K1A. Sci Rep. 2017; 7:9438. https://doi.org/10.1038/s41598-017-09633-Z. [PubMed]

30. de la Puente P, Azab F, Muz B, Luderer M, Arbiser J, Azab AK. Tris DBA palladium overcomes hypoxia-mediated drug resistance in multiple myeloma. Leuk Lymphoma. 2016; 57:1677-86. https://doi.org/10.3109/10428194.2015 1099645. [PubMed]

31. Kumar S, Singh B, Dimmock JR, Sharma RK. $\mathrm{N}$-myristoyltransferase in the leukocytic development processes. Cell Tissue Res. 2011; 345:203-11. https://doi. org/10.1007/s00441-011-1202-x. [PubMed]

32. Raju RV, Moyana TN, Sharma RK. N-Myristoyltransferase overexpression in human colorectal adenocarcinomas. Exp Cell Res. 1997; 235:145-54. https://doi.org/10.1006/ excr.1997.3679. [PubMed]
33. Jorjani H, Kehr S, Jedlinski DJ, Gumienny R, Hertel J, Stadler PF, Zavolan M, Gruber AR. An updated human snoRNAome. Nucleic Acids Res. 2016; 44:5068-82. https://doi.org/10.1093/nar/gkw386. [PubMed]

34. Sundqvist A, Morikawa M, Ren J, Vasilaki E, Kawasaki N, Kobayashi M, Koinuma D, Aburatani H, Miyazono K, Heldin CH, van Dam H, Ten Dijke P. JUNB governs a feedforward network of TGF $\beta$ signaling that aggravates breast cancer invasion. Nucleic Acids Res. 2018; 46:1180-95. https://doi.org/10.1093/nar/gkx1190. [PubMed]

35. Bhandarkar SS, Bromberg J, Carrillo C, Selvakumar P, Sharma RK, Perry BN, Govindarajan B, Fried L, Sohn A, Reddy K, Arbiser JL. Tris (dibenzylideneacetone) dipalladium, a N-myristoyltransferase-1 inhibitor, is effective against melanoma growth in vitro and in vivo. Clin Cancer Res. 2008; 14:5743-5748. https://doi.org/10.1158/1078-0432. CCR-08-0405. [PubMed]

36. Elsey J, Bubley JA, Zhu L, Rao S, Sasaki M, Pollack BP, Yang L, Arbiser JL. Palladium based nanoparticles for the treatment of advanced melanoma. Sci Rep. 2019; 9:3255. https://doi.org/10.1038/s41598-019-40258-6. [PubMed] 